\title{
ULTRASOUND IMAGING AND SECONDARY SCREENING FOR CONGENITAL DISLOCATION OF THE HIP
}

N. R. BOEREE, N. M. P. CLARKE

From Southampton University Hospitals NHS Trust, England

We report the preliminary results of a continuing prospective evaluation of a screening programme for congenital dislocation of the hip (CDH) which uses ultrasound imaging to provide delayed selective screening to complement neonatal clinical screening. Of 26952 births in the Southampton district, 1894 infants were referred for secondary screening because of a clinical abnormality or the presence of a predetermined risk category for $\mathrm{CDH}$.

Pavlik harness treatment was required for only 118 infants, giving a treatment rate of 4.4 per 1000 births. Of those referred with clinical instability, $35 \%$ did not require treatment. Dislocation or subluxation was detected in 17 of 643 infants referred only because they fell within one of three risk categories: breech presentation, foot deformity and family history. All 17 had normal clinical examinations and cases were discovered in each category.

Six children presented with $\mathrm{CDH}$ after 12 weeks of age, giving a late presentation rate of 0.22 per 1000 births. All had normal clinical examinations within 24 hours of birth and none was in a risk category. Surgery has been required in ten children, giving a surgical treatment rate of 0.37 per 1000 births.

We conclude that, in Southampton, delayed selective secondary screening with ultrasound is more effective than clinical screening alone. It targets treatment to those infants who need it, and reveals a number of dislocated and subluxed hips that would otherwise be missed.

J Bone Joint Surg [Br] 1994; 76-B:525-33.

Received 13 January 1994; Accepted 2 March 1994

N. R. Boeree, BSc, FRCS, FRCS Ed, Senior Orthopaedic Registrar N. M. P. Clarke, ChM, FRCS, FRCS Ed, Consultant Orthopaedic Surgeon Southampton General Hospital, Tremona Road, Southampton SO9 4XY, UK.

Correspondence should be sent to Mr N. M. P. Clarke.

(C1994 British Editorial Society of Bone and Joint Surgery $0301-620 \mathrm{X} / 94 / 4838 \$ 2.00$
Clinical screening for congenital dislocation of the hip (CDH) was recommended in the UK by the Department of Health in 1969 and the advice was updated in 1986. Despite the almost universal adoption of this policy, however, there has been only a marginal impact on the number of children requiring surgery for $\mathrm{CDH}$. In the absence of routine screening about 1 child per 1000 births will eventually require operation for established subluxation or dislocation (Severin 1956; Harris, Lipscomb and Hodgson 1960; Lehmann and Street 1981; MacKenzie and Wilson 1981). Some screening policies have achieved a significant reduction (von Rosen 1968; Hiertonn and James 1968; Mitchell 1972) but most studies report broadly similar numbers of children requiring at least one surgical procedure, principally due to a persisting and significant incidence of late-presenting $\mathrm{CDH}$ (Bjerkreim 1974; MacKenzie and Wilson 1981; Dunn et al 1985; Lennox, McLauchlan and Murali 1993). Clinical screening thus seems to lack sensitivity, producing a high rate of false-negative examinations (Leck 1986).

The baseline of 1 per 1000 children requiring surgery from an unscreened population can be used to judge the rates of splintage in a screened population. Splintage rates in excess of this must represent a degree of overtreatment, but reported rates vary considerably. Dunn et al (1985) found that abduction splintage was undertaken in 19 infants per 1000 births; clearly, far more were treated than would ultimately have required surgery. Thus, early clinical screening has a high rate of false-positive results; it is non-specific (Leck 1986). The major cause must be the spontaneous resolution of the majority of clinically unstable hips detected at neonatal examination (Barlow 1962), yet treatment cannot be based on a delayed clinical examination, since negative findings at this stage do not imply that a hip is normal (Clarke 1986). Early splintage carries a small but significant risk of avascular necrosis and other complications (Kalamchi and MacEwen 1980; Bradley, Wetherill and Benson 1987; Langkamer, Clarke and Witherow 1991), and also has resource implications.

Ultrasound examination offers a reliable, safe and non-invasive method of imaging the neonatal hip. It can be used as a primary screening tool, with the objective of eliminating all false-negative examinations. For this, all neonates would have to be screened, and the considerable cost and logistical implications of such an undertaking would be compounded by the high prevalence of hip 


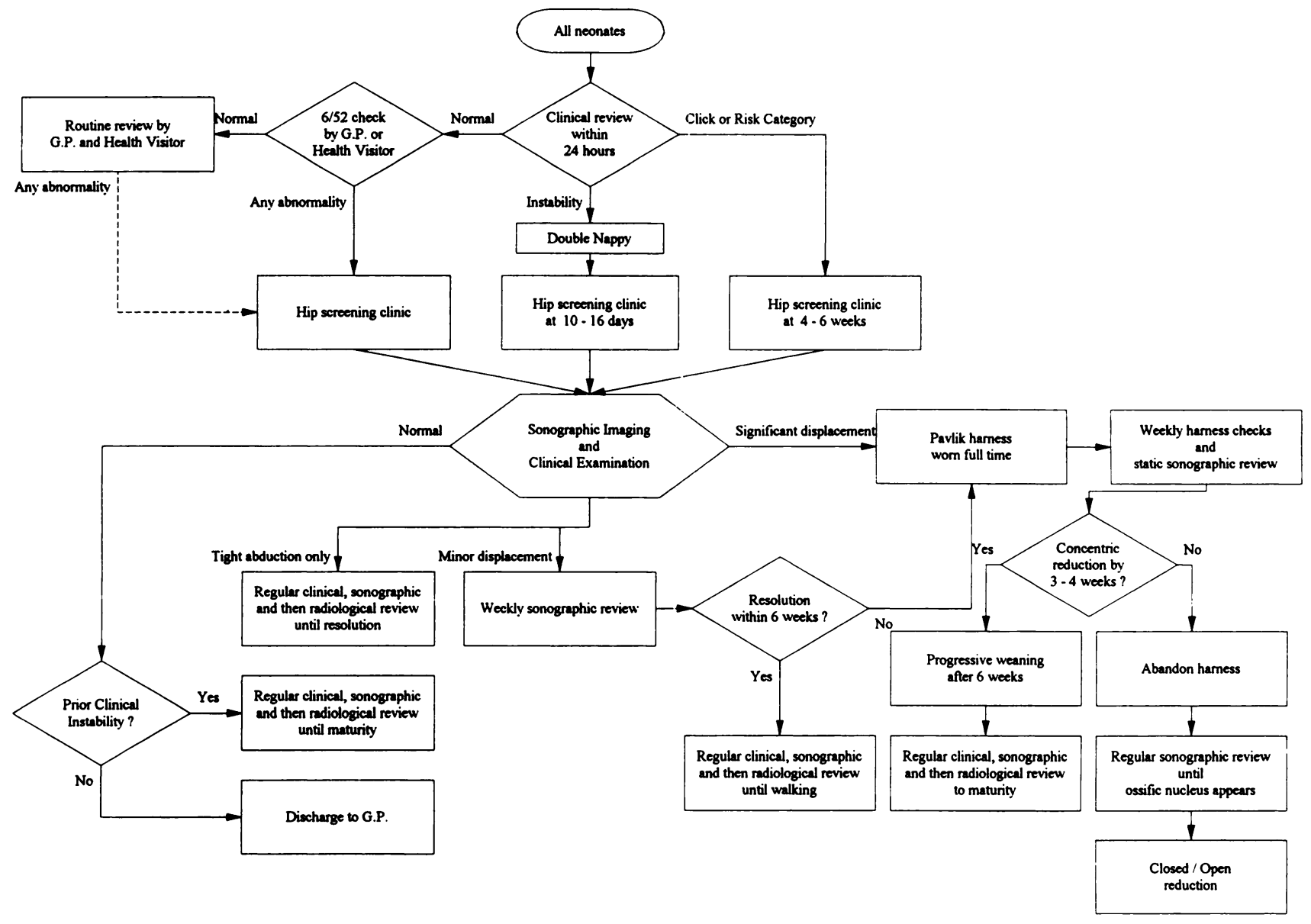

Fig. 1

Algorithm showing the design of the study in terms of decisions.

Table I. Annual live birth rate in the Southampton district related to the number of infants referred for the secondary screening programme

\begin{tabular}{|c|c|c|c|c|}
\hline \multirow[b]{2}{*}{ Year } & \multirow{2}{*}{$\begin{array}{l}\text { Births in } \\
\text { district }\end{array}$} & \multicolumn{2}{|c|}{ Number screened } & \multirow{2}{*}{$\begin{array}{l}\text { Screened per } \\
1000 \text { births }\end{array}$} \\
\hline & & Total & Male/Female & \\
\hline 1988 (7 mth) & 3454 & 144 & $61 / 83$ & 41.7 \\
\hline 1989 & 5881 & 467 & $198 / 269$ & 79.4 \\
\hline 1990 & 6022 & 366 & $140 / 226$ & 60.8 \\
\hline 1991 & 5804 & 489 & $191 / 298$ & 84.3 \\
\hline 1992 & 5791 & 428 & $194 / 234$ & 73.9 \\
\hline Total & 26952 & 1894 & $784 / 1110$ & 70.3 \\
\hline
\end{tabular}

abnormalities detected by early sonography. Tönnis, Storch and Ulbrich (1990) reported that neonatal sonographic screening revealed one-third of all hips to be either frankly pathological or so physiologically immature that their dysplastic potential demanded further review. Overtreatment could only be avoided by rescreening one to two weeks later.

Alternatively, ultrasound imaging can be used as a secondary diagnostic test to supplement primary clinical screening. This would detect false-positive results and thus reduce overtreatment. It would also require less immediate resources but would do little to address the problem of late-presenting $\mathrm{CDH}$, the false-negative failures of clinical screening.

We have used ultrasound imaging to try to address both problems by a programme of delayed, selective, secondary screening. First, we used diagnostic imaging at two weeks of all hips showing early clinical instability; this allowed treatment to be targeted to those with persisting instability. Secondly, we used ultrasound as a screening examination to complement clinical examination by imaging all hips with minor abnormalities, such as a click, and those with recognised risk factors for $\mathrm{CDH}$, even if clinical examination was normal. We now report the preliminary results of this continuing prospective evaluation, started in June 1988.

\section{PATIENTS AND METHODS}

In the Southampton health district $99 \%$ of all births take place at the Princess Anne Maternity Hospital. From June 1988 to December 1992 there were 26952 live births (Table I). These form the cohort for the prospective study. An algorithm of the strategies for screening and treatment is shown in Figure 1. 
Screening for CDH. All infants born at the Princess Anne Maternity Hospital have a comprehensive postnatal examination by a paediatrician, when possible within 24 hours of birth. This examination includes both the Ortolani (1937) and the Barlow (1962) tests for hip instability, and a history is taken from the mother of any family history of hip instability. All hip abnormalities are recorded, including instability, hip click or clunk, and apparent limitation of abduction.

Instability at the postnatal clinical examination is treated by the use of a double nappy to maintain the hips in abduction. Prone lying has been abandoned because of its association with sudden infant death syndrome. Arrangements are made for attendance at the Hip Screening Clinic at between 10 and 16 days of age. Those with less severe abnormalities such as a hip click and those in a recognised risk category are also referred to the Hip Screening Clinic, but are seen between 4 and 6 weeks of age. The categories with increased risk for $\mathrm{CDH}$ include:

1) breech presentation at delivery (vaginal or caesarean);

2) foot deformity (structural or positional); and

3) a positive family history of hip instability or displacement.

All other infants are examined at six weeks of age by a health visitor or a general practitioner. If any hip abnormality is suspected the child is referred to the Hip Screening Clinic. All general practitioners, midwives and health visitors are kept informed of the open availability of the clinic and of the importance of referring all hip abnormalities, including limitation of hip abduction, apparent leg-length inequality and asymmetry of the thigh or buttock skin creases.

At the Hip Screening Clinic all relevant details are recorded including date and place of birth, birth rank, type of delivery, cephalic or breech presentation, and the reason and source of referral. The findings at postnatal and subsequent examinations are recorded. A thorough general examination of the infant records any craniofacial moulding, spinal anomalies or foot deformities. The hips are examined for instability; clicks in either hip and any limitation in abduction are recorded.

Sonographic examination of both hips includes static and dynamic assessment (Clarke et al 1985), and each hip is graded as 'dislocated', 'subluxed', 'minimally displaced' or 'located'. Any retardation of acetabular growth in an otherwise stable and located hip is also recorded.

Management. Infants with no clinical abnormality of the hips and normal findings on sonography are discharged after the parents have been reassured. In a few infants the hips are tighter than normal in abduction, although otherwise clinically and sonographically normal; they are kept under regular review until the tightness has fully resolved, with ultrasound imaging and, when appropriate, radiography to exclude the development of acetabular dysplasia.

Minor sonographic displacement with or without acetabular growth retardation is regarded as evidence of probable resolving instability; monitoring continues until satisfactory resolution is seen. Failure to resolve fully by six weeks is an indication for splintage. Most such cases, however, resolve completely, but the children are kept under regular review until they are walking normally and radiographs have demonstrated normal, symmetrical development of the hip. Prior instability may also result in a degree of acetabular growth retardation although at the time of examination the hips will be noted to be stable and to be concentrically reduced. These children are reviewed in a similar manner to ensure normal hip development.

When ultrasound shows significant displacement of a hip at the initial attendance the infant is treated in a Pavlik harness, initially on a full-time basis. A specially trained physiotherapist instructs the mother in the care of the harness, and checks and adjusts it each week when the child returns for ultrasound monitoring.

Ultrasound imaging is performed each week to ensure satisfactory relocation. This is a simple static examination, undertaken with the infant in the harness. Provocative testing is avoided. When a concentric reduction has been achieved and maintained, the child is gradually weaned from the harness, initially for one hour each day, then for increasing periods until it is worn only at night. Night treatment is then continued until it is no longer tolerated by the child. Throughout the period of weaning sonographic monitoring and checking and adjusting of the harness continue on a weekly basis.

Should the hip not reduce concentrically within the first 3 to 4 weeks, or at least show good progress towards reducing concentrically, harness treatment is abandoned. The development of the hip is then monitored until ultrasound shows the appearance of an ossific nucleus. Closed reduction is then attempted and open reduction is undertaken should this fail.

Prospective records were kept of the primary method of management and the outcome for those treated by Pavlik harness including the time in weeks to achieve concentric location and the time until weaning started. When satisfactory location was not achieved, the time at which harness treatment ceased was recorded. For infants monitored sonographically for minor displacement we recorded the time in weeks to concentric stabilisation, or if this was not achieved the outcome of subsequent harness treatment.

Non-attenders. Failure to attend the screening clinic was managed by a letter to the parents, explaining the importance of examining their child's hips and the safety of ultrasound screening, and offering an appointment for the following week. This was repeated once. If the child failed to attend two rescheduled appointments the matter was referred to the general practitioner who was asked to attempt, through personal contact, to persuade the parents. Late referrals. Our prospective orthopaedic records cover all children born between June 1988 and December 


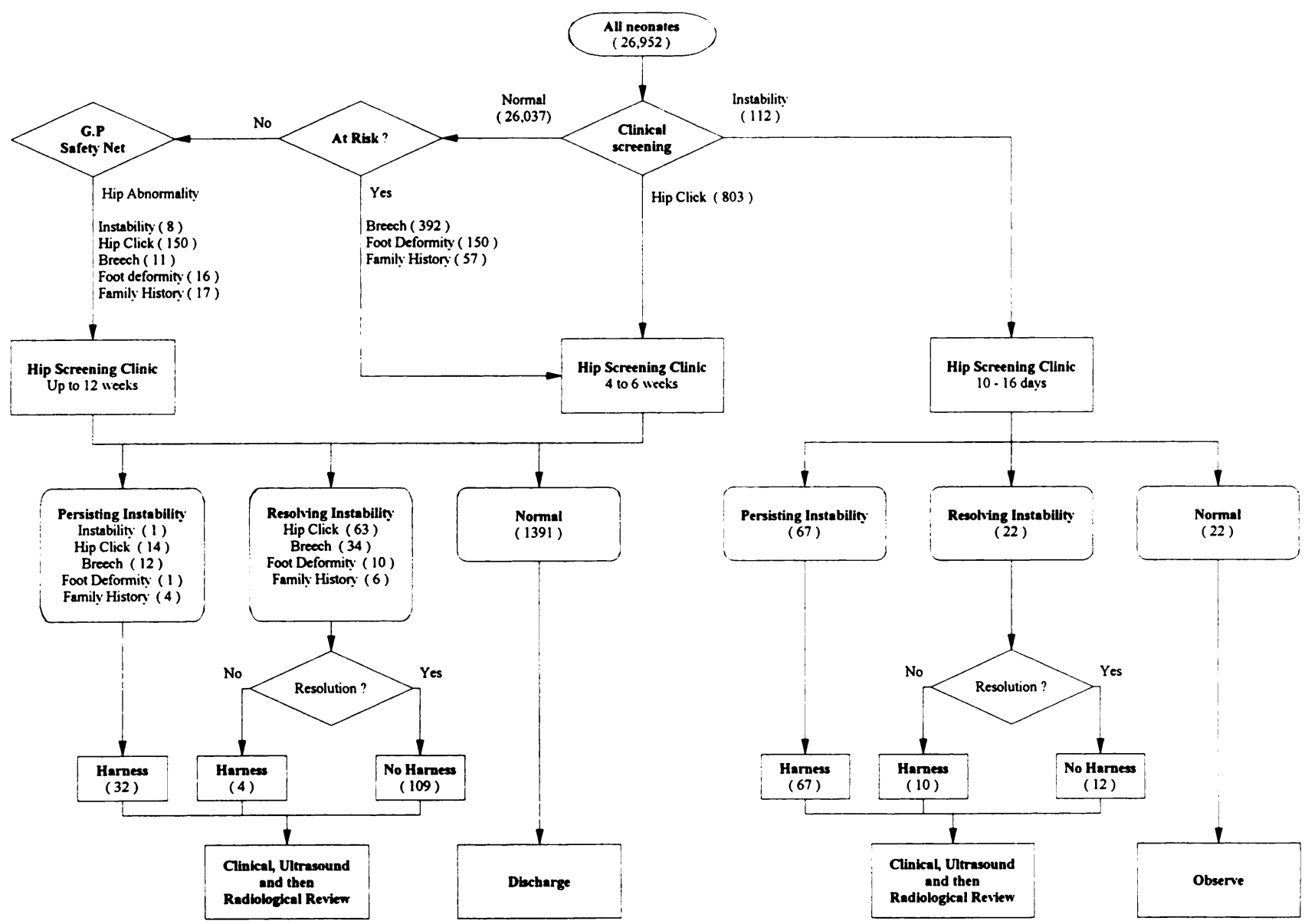

Fig. 2

Algorithm showing results in terms of numbers of infants.

1992 who have been referred to the paediatric orthopaedic clinic with any hip-related problem, particularly those with late-presenting $\mathrm{CDH}$. To our knowledge no child born in the Southampton district during this period has been treated for late-presenting $\mathrm{CDH}$ elsewhere. For the purposes of this study we define late-presenting $\mathrm{CDH}$ as any dislocation or subluxation presenting after the age of 12 weeks. In our experience, conservative treatment by a Pavlik harness beyond this age is increasingly unlikely to be successful.

Retrospective analysis of surgery for CDH. We analysed retrospectively the records of all children born between January 1978 and December 1987 in the Southampton district and treated for $\mathrm{CDH}$. During this period routine clinical screening for $\mathrm{CDH}$ was undertaken, but treatment was deferred until an ossific nucleus became apparent on radiographic examination. The analysis focused on the number of cases of $\mathrm{CDH}$ treated and the operations on this population undertaken, so that we could compare the surgical treatment rate for $\mathrm{CDH}$ observed in a screened population before and after the introduction of early splintage treatment for instability.

Data collection. Data for all infants who were referred to the Hip Screening Clinic were recorded prospectively in a standard format in the medical records. The data were collected on an IBM-compatible personal computer using a specially developed relational database application based on Paradox 4.0.

\section{RESULTS}

Of the 26952 children born at the Princess Anne Maternity Hospital from June 1988 to December 1992 a total of 1894 (7.0\%) have been referred to the Hip Screening Clinic (Table I). Of these 1110 were female and 784 male; $1583(83.6 \%)$ were referred by paediatricians and 311 (16.4\%) by general practitioners. The detailed numbers at each stage are shown in Figure 2.

Attendance rate. The attendance rate for the Hip Screening Clinic was $95.8 \%$, with a slightly higher rate for infants with detected hip abnormalities than for those in the risk categories $(96.5 \%$ and $94.6 \%$ respectively; $\mathrm{p}=0.0503$ ).

Reasons for referral. Of referrals by paediatricians (Table II), $51 \%$ were because of a click on examination of the hip and $38 \%$ because of an associated risk factor 
Table II. Reasons for referral for secondary screening, by number and percentage

\begin{tabular}{lcc}
\hline & Paediatrician & General practitioner \\
\hline Hip abnormalities & $112(7.1)$ & $8(2.6)$ \\
Instability & $803(50.7)$ & $150(48.2)$ \\
Click & $34(2.1)$ & $78(25.1)$ \\
Abduction limit & $6(0.4)$ & $22(7.1)$ \\
Leg asymmetry & & \\
At risk & $392(24.8)$ & $11(3.5)$ \\
$\quad$ Breech presentation & $57(3.6)$ & $17(5.5)$ \\
$\quad$ Family history & $150(9.5)$ & $16(5.1)$ \\
Foot deformity & & \\
Other & $12(0.8)$ & 0 \\
$\quad$ Multiple pregnancy & $17(1.1)$ & $9(2.9)$ \\
$\quad$ Various & 1583 & 311 \\
Total &
\end{tabular}

although the infant was clinically normal. Only $7 \%$ were because of suspected hip instability on the Ortolani or Barlow tests.

Of general practitioner referrals (Table II) the alerting sign in $25 \%$ was a reduced range of hip abduction but a hip click remained the most frequent reason for referral (48\%).

Instability. Of 120 infants referred with suspected hip instability, $112(93 \%)$ were referred by paediatricians as a result of primary clinical screening and $8(7 \%)$ by general practitioners. One infant, a paediatric referral, failed to attend. Ultrasound imaging at two weeks showed that in 29 infants $(24.4 \%)$ the hips had stabilised and were concentrically located and in the other $22(18.5 \%)$ there was only minimal displacement of one or both hips. In the remaining 68 infants $(57.1 \%)$ one or both hips were confirmed sonographically to be subluxed or dislocated.

In the 112 infants referred by paediatricians 177 hips were clinically unstable at neonatal examination; instability was unilateral in 45 infants and bilateral in 66 . Of the 176 initially unstable hips that were re-examined clinically at two weeks before sonographic imaging, 136 (77.2\%) had no apparent instability and were considered to be clinically normal. Sonographic examination showed that $55(40.4 \%)$ of these clinically resolved hips were subluxed or dislocated. In the 45 infants considered to have only unilateral instability, ultrasound examination revealed unsuspected subluxation or dislocation of the contralateral hip in six $(13.3 \%)$.

Of those referred for hip instability, $42(35 \%)$ did not require treatment. Harness treatment was used for 78 infants: in 68 this was primary treatment for hip subluxation or dislocation, and in 10 infants it was for minor displacement which had failed to resolve by six weeks.

Hip clicking. A total of 953 infants were referred because a click had been detected; 919 attended the clinic. Of these referrals, 803 were from paediatricians and 150 from general practitioners. Ultrasound imaging showed that $14(1.5 \%)$ of the 919 infants had dislocation or subluxation, with four bilateral cases. Another 63 were shown to have minor displacement or retardation of acetabular growth. One case with only minor displacement failed to stabilise and required subsequent treatment by a harness. Thus, a total of 15 infants in this group required harness treatment.

Breech presentation. A total of 403 infants had clinically normal hips but were referred because of breech presentation. This group does not include those who were breech presentations but had clinical abnormalities such as a click or instability. Most of the infants referred after breech presentation (264) had been delivered by caesarean section.

Of these 403 infants, 11 were referred by general practitioners and 392 by paediatricians; 27 did not attend. Of the 376 attenders, 34 (9\%) showed evidence of resolving or previous instability and another $12(3.2 \%)$ had a total of 18 subluxed or dislocated hips. These 12 infants were treated by harness.

Foot deformity. At postnatal examination (150) or at the six-week check (16) a total of 166 infants with clinically normal hips had structural or positional foot deformities. Six failed to attend for orthopaedic review. All the 160 infants who attended for the foot problem were also screened for hip displacement. One child $(0.63 \%)$ had a subluxed hip and was treated in a harness. Ten others (6.3\%) had some residual displacement; two of these failed to resolve spontaneously and required harness treatment.

Positive family history. A positive family history of $\mathrm{CDH}$ or hip dysplasia was obtained from the parents of 74 infants with normal clinical findings. The family history related to a sibling in 36 , to a parent in 26 , to a grandparent in one, and to a more distant relative in 11 . One did not attend for ultrasound screening. Of the remaining 73 , six (8.2\%) had residual minor displacement and four (5.5\%) had subluxation which was bilateral in three. These four infants were all treated in a harness as was one with minor displacement which failed to resolve.

We obtained a positive family history in 197 cases and $40(20.3 \%)$ had some sonographic evidence of instability: $21(10.7 \%)$ with subluxation or dislocation of one or both hips and $19(9.6 \%)$ with residual minor displacement or retardation of acetabular growth. We found no statistically significant difference in the incidence of instability between those with an affected close relative (sibling or parent) and those whose family history related to a more distant relative.

Of the remainder of the cohort (26755 infants) with no family history of hip instability or displacement 1568 (5.9\%) were examined sonographically. Of these 163 $(0.61 \%)$ had some evidence of instability: $127(0.47 \%)$ had minor displacement and $36(0.13 \%)$ had subluxation or dislocation of one or both hips. This difference in the incidence of instability between those with a positive family history and those without is statistically significant $(p<0.0001)$. Of all infants with subluxation or dislocation $20.8 \%$ had a positive family history. 
The general practitioner 'safety net'. In 28 cases, the presence of risk factors was not appreciated at the postnatal examination but was detected by the general practitioner at six weeks. In 17 a positive family history was elicited and 11 had been breech presentations. Another 16 infants had been referred by the general practitioner because of a possible foot deformity which had not been noted at birth; none of these 44 infants in risk categories had a dislocated or subluxed hip on ultrasound examination.

Five children with subluxed or dislocated hips were detected as a result of general practitioner referrals. In one, clinical instability of one hip was suspected at six weeks and confirmed sonographically. The other four had been found by their general practitioner to have a hip click, representing $2.7 \%$ of all general practitioner referrals for this reason.

Gender and birth rank. More than five times as many females as males had sonographic evidence of major displacement. Slightly more infants with subluxation or dislocation were first-born (birth rank 1: 46, 2: 32, 3: 14, 4: 9 and 5: 1) but the distribution of the different birth ranks was not significantly different in the referred population with no significant displacement. A control population for the relative incidence of the distribution of birth ranks was not available.

Treatment by Pavlik harness. Since June 1988, from the 26952 births in the Southampton district, 118 infants have been treated for CDH by Pavlik harness (Table III). This is a treatment rate of 4.4 per 1000 births. Of these, 98 were treated primarily after the sonographic detection of hip subluxation or dislocation, and 20 started harness treatment when weekly sonographic monitoring showed failure of satisfactory stabilisation of minor displacement.

There have been no cases of avascular necrosis and no other complications arising from treatment by Pavlik harness.

Late referrals and late-presenting $\mathrm{CDH}$. In addition to the 1894 infants referred to the Hip Screening Clinic another 218 born in the Southampton district were subsequently referred to the paediatric orthopaedic clinic because of concern about one or both hips, at over 12 weeks of age.

Six cases of late-presenting $\mathrm{CDH}$ were seen after the age of 12 weeks, representing an overall incidence of 0.22 per 1000 live births (Table IV). Their mean age at presentation was 10.5 months ( 3 to 17 ; SD 4.76). None of the six children had any hip abnormality detected at postnatal or six-week screening. All had postnatal examination within 24 hours of birth and none fell within any of the predetermined risk categories. None was firstborn and the mean birth rank was 3.25 . Of the 80 infants who failed to attend the Hip Screening Clinic none has since presented with any significant hip pathology.

The minimum interval from birth for the cohort as a whole is now 12 months and exceeds 24 months for $77 \%$. A single-tailed $t$-distribution with five degrees of freedom for the six children allows the calculation of the probability of undetected cases of $\mathrm{CDH}$ presenting at various ages. The number of births in each month since the beginning of the study is known and thus, using the present incidence of late-presenting cases for the cohort of 6 per 26952 births, the probabilities of a late-presenting case now

\begin{tabular}{|c|c|c|}
\hline \multirow[b]{2}{*}{ Year } & \multicolumn{2}{|c|}{ Treated by harness } \\
\hline & Number & Per 1000 births \\
\hline 1988 (7 mth) & 12 & 3.5 \\
\hline 1989 & 22 & 3.74 \\
\hline 1990 & 31 & 5.15 \\
\hline 1991 & 32 & 5.51 \\
\hline 1992 & 21 & 3.63 \\
\hline Total & 118 & 4.38 \\
\hline
\end{tabular}

Table IV. Details of the six infants presenting with $\mathrm{CDH}$ after the age of 12 weeks

\begin{tabular}{|c|c|c|c|c|c|c|c|}
\hline Case & Sex & Born & $\begin{array}{l}\text { Referred } \\
\text { (mth) }\end{array}$ & Side & $\begin{array}{l}\text { Age at } \\
\text { postnatal } \\
\text { examination (hr) }\end{array}$ & $\begin{array}{l}\text { 6-week } \\
\text { check }\end{array}$ & Surgery \\
\hline 1 & $\mathbf{F}$ & 1989 & 13 & Left & $<24$ & Yes & $\begin{array}{l}\text { Adductor tenotomy and closed reduction } \\
\text { Salter pelvic osteotomy }\end{array}$ \\
\hline 2 & $\mathbf{F}$ & 1990 & 10 & Right & $<24$ & Yes & $\begin{array}{l}\text { Adductor tenotomy } \\
\text { Open reduction }\end{array}$ \\
\hline 3 & $\mathbf{F}$ & 1990 & 17 & Right & $<12$ & Yes & $\begin{array}{l}\text { Adductor tenotomy } \\
\text { Open reduction }\end{array}$ \\
\hline 4 & $\mathbf{F}$ & 1990 & 3 & Left & $<24$ & Yes & $\begin{array}{l}\text { Harness treatment unsuccessful, therefore adductor tenotomy and } \\
\text { closed reduction } \\
\text { Salter pelvic osteotomy }\end{array}$ \\
\hline 5 & $\mathbf{F}$ & 1990 & 8 & Left & $<12$ & Yes & $\begin{array}{l}\text { Adductor tenotomy and closed reduction } \\
\text { Salter pelvic osteotomy }\end{array}$ \\
\hline 6 & $\mathbf{F}$ & 1992 & 12 & Left & $<24$ & Yes & Pending \\
\hline
\end{tabular}


being discovered can be calculated for each month. The current overall probability of a further case of latepresenting $\mathrm{CDH}$, derived from the sum of these probabilities, is $0.021 \%$. As might be anticipated, the principal component of this risk relates to those infants born in the most recent months. If no further cases are discovered during the next four months the risk will be more than halved to $0.008 \%$.

Surgical procedures. Ten children have required surgery, five after failure of harness treatment and five because of late presentation. One other child is awaiting treatment and will require at least an adductor tenotomy before attempted closed reduction. Thus, the incidence of surgical treatment for children born during the period of the study has been 0.37 per 1000 births but will rise to 0.4 per 1000 . To date these children have undergone 24 surgical procedures (Table V).

Retrospective analysis 1978 to 1987 . Our retrospective analysis showed that during the years 1978 to 1987 , there were 47180 live births in the Southampton district. From this population only, at least 77 ( 62 females and 15 males) had operations for $\mathrm{CDH}$. The average incidence of surgical treatment for $\mathrm{CDH}$ over this ten-year period was therefore 1.63 per 1000 births. A total of 328 operations were performed on these infants (Table VI).

\section{DISCUSSION}

The early optimism after the adoption of clinical screening for $\mathrm{CDH}$ was based on confidence in the tests described by Ortolani (1937) and by Barlow (1962). In the 1970s doubt was cast on the overall effectiveness of clinical screening (MacKenzie 1972; Williamson 1972; Bjerkreim 1974; Place, Parkin and Fitton 1978). Despite greater awareness and improved experience concerns have continued about the difficulty of ensuring effective screening, and the persisting incidence of late-presenting cases (MacKenzie and Wilson 1981; Burger et al 1990; Lennox et al 1993). At some centres where clinical screening is pursued enthusiastically, the remarkable results reported in earlier years have not been maintained (Sanfridson, Redlund-Johnell and Udén 1991).

Clinical screening in the early neonatal period will detect many more abnormal hips than require treatment: very many unstable hips will resolve spontaneously to normal (Barlow 1962). In the absence of routine clinical screening about 1 child per 1000 will ultimately require surgery (Severin 1956; Harris et al 1960; Lehmann and Street 1981; MacKenzie and Wilson 1981); and this is many fewer than the rate of up to 36 per 1000 who will be treated in a splint on the basis of abnormality at postnatal examination (Hiertonn and James 1968; Dunn et al 1985; Sanfridson et al 1991). Splintage is not without risks: avascular necrosis of the capital epiphysis, epiphysitis and full-thickness pressure sores are recognised complications in a small proportion of treated infants (Kalamchi and MacEwen 1980; Bradley et al 1987;
Table V. Operations for CDH, June 1988 to December 1992. Bilateral procedures are recorded twice

\begin{tabular}{ll}
\hline Procedure & Number \\
\hline Adductor tenotomy & 10 (2 bilateral) \\
Open reduction & 6 \\
Salter pelvic osteotomy & 3 \\
Varus femoral osteotomy & 1 \\
Removal of metal & 4 \\
\hline
\end{tabular}

Table VI. Operations for CDH on infants born in Southampton from January 1978 to December 1987. Bilateral procedures are recorded twice

\begin{tabular}{ll}
\hline Procedure & Number \\
\hline Adductor tenotomy & 70 (25 bilateral $)$ \\
Open reduction & 77 \\
Open reduction with pelvic osteotomy & 14 \\
Open reduction with femoral shortening & 1 \\
Pelvic osteotomy & 81 \\
Pelvic osteotomy with psoas transfer & 3 \\
Pelvic osteotomy with femoral shortening & 1 \\
Femoral osteotomy & 8 \\
Removal of metal & 73 \\
\hline
\end{tabular}

Langkamer et al 1991). The number of children who are treated unnecessarily (the false-positive rate) cannot be dismissed as inconsequential.

Although clinical screening results in treatment of many more children than would have developed $\mathrm{CDH}$, a significant number of cases continue to be missed. Their hips appear to be clinically normal at birth but they present later with a dislocation that can no longer be treated by simple splintage. Dunn et al (1985) reported a late-presenting $\mathrm{CDH}$ rate of 0.44 per 1000 births, and the incidence in Malmö between 1980 and 1987 was 0.6 per 1000 (Sanfridson et al 1991). These are the false-negative results of a screening programme and most children will require some form of surgery.

One option is to restrict treatment to those with a clinical abnormality which persists when the hip is reexamined at a later stage, and this allows for the spontaneous resolution of a proportion of cases of early instability. It would achieve a modest reduction in treatment rate, but at the probable cost of a considerable increase in late-presenting cases. We found that $77 \%$ of all initially unstable hips had become clinically stable when re-examined at two weeks, but $40 \%$ of these remained subluxed or dislocated on sonographic imaging.

Clinical examination may fail to detect hip instability or dislocation for a number of reasons. The hip may be irreducible. Signs of instability may disappear soon after 
birth or may be too subtle to be appreciated, particularly by an inexperienced observer. After two or three weeks there may be no clinical abnormality on examination, but it has been shown that a normal examination at this stage does not imply that the hip is normal (Clarke 1986); this observation has been confirmed by the current study.

Ultrasound imaging offers a quick, safe and reliable method of addressing the shortcomings of clinical examination, either as a screening tool taking the place of clinical examination, or as a diagnostic aid which supplements primary clinical screening.

Its use as a primary screening technique requires substantial resource and logistic support, especially in a larger unit. Screening before the infant leaves hospital, surveying a captive population, requires imaging facilities and the necessary skills to be available for at least six, and preferably seven days a week. At this stage, imaging will detect a high proportion of hip abnormalities, much more than clinical screening and in up to one-third of all infants (Tönnis et al 1990). Treatment based on this initial evaluation would result in an unacceptable rate of over 300 infants per 1000 births. Alternatively, all these infants will have to be recalled for re-examination. If this had been applied in Southampton, an average of 16 initial scans would have been required every day, another 16 would have required rescanning each week, and many of these would require regular review to ensure satisfactory resolution.

There is a case for ultrasound screening of all infants at two weeks, on the basis that by then transient hip instability will have resolved. This will reduce the number of false-positive cases which would otherwise have been treated, but the number to be screened will still be large and there is likely to be a high default rate. The high cost of recalling all infants is likely to be prohibitive.

If ultrasound is to be used as a diagnostic aid to primary clinical screening some consideration must be given to which groups of infants are selected for imaging. All those with clinical evidence of instability must be checked, preferably early enough for conservative treatment to have a high chance of success. There are advantages in delaying secondary screening for two weeks; fewer infants need treatment because of spontaneous resolution of a proportion of cases of early instability. In our series no infant with sonographically resolved instability developed $\mathrm{CDH}$.

Debate continues about the significance of a click in an otherwise stable hip (Cunningham et al 1984; Dunn 1984; Dunn et al 1985). In an earlier study we showed that a proportion of such hips will have a significant abnormality when imaged by ultrasound (Clarke, Clegg and Al-Chalabi 1989). The new study has again confirmed that hip clicks cannot be ignored: they were the commonest reason for referral and significantly increased the secondary screening workload, but $1.5 \%$ of infants (14 cases) were found to have dislocation or subluxation of one or both hips.
We have also shown the importance of checking infants who are at an increased risk of $\mathrm{CDH}$, even when there is no abnormality on early clinical examination. In the recognised higher-risk groups a covert major hip displacement was shown by ultrasound in 17 cases. There were positive findings in each of the risk groups, with incidences varying from $0.6 \%$ to $5.5 \%$.

The incidence of $\mathrm{CDH}$ in first-born infants is reported to be twice normal, and girls have a fourfold increase in risk when compared with boys (Dunn et al 1985). We found an even greater relative risk for girls: all six cases of late-presenting $\mathrm{CDH}$ were girls. The inclusion of female sex as a risk category for secondary screening would have eliminated all our late-presenting cases, if it is assumed that sonographic instability would have been detectable at early examination. The practical drawbacks, however, of an increased load, discussed earlier, would be considerable. By contrast, we predict no practical gain from screening all first-born infants; we did not confirm a significant increase in the incidence of instability in this group. None of the six late-presenting cases was firstborn and their average birth rank was high, at 3.2.

We earlier reported the results of a one-year programme in which only high-risk cases had delayed secondary ultrasound screening, irrespective of clinical findings (Clarke et al 1989). We detected a number of major hip displacements in these higher-risk infants but failed to achieve a reduction in the incidence of latepresenting cases. The rate for the year in question was 0.72 per 1000 live births.

Our current protocol for selective ultrasound screening depends on effective primary clinical screening. In an infant who does not fall within the selection criteria but then presents later with an established dislocation either the diagnosis was missed or there was no clinical abnormality at the time of examination. In Southampton over four years, this protocol has achieved a considerably lower incidence of late-presenting $\mathrm{CDH}$ of 0.22 per 1000 children born.

Our new screening protocol has resulted in an overall treatment rate of 4.4 per 1000 live births. Compared with the 0.8 to 1.6 per 1000 who might ultimately require surgery for $\mathrm{CDH}$, derived from series with no routine screening, this must still be considered as overtreatment. It is, however, considerably lower than the treatment rates resulting from early clinical screening only. Dunn et al (1985) splinted 19 infants per 1000 births, while over recent years in Malmö treatment rates have varied from 12 to 36 per 1000 births (Sanfridson et al 1991).

From 1972 to 1988, it was decided to abandon the early splinting of hip instability in Southampton because it was considered that the risk of avascular necrosis was unacceptably high (Catford, Bennet and Wilkinson 1982). Surgical treatment for $\mathrm{CDH}$ during this period was at a rate of 1.6 per 1000 births, very similar to that observed among unscreened European, Scandinavian and North American populations. The introduction of dual screening 
and early treatment for $\mathrm{CDH}$ in Southampton has resulted in a very significant fall, to $0.4 \%$, in the need for operation.

Neonatal instability probably represents an early stage in the process that leads to hip dislocation. This process is certainly not inevitable, but it is not yet known if there are categories or types of instability which may be safely left untreated. Our study indicates that early clinical instability which ultrasound later confirms to have resolved completely does not recur. Ultrasound monitoring allows minor degrees of displacement to be left untreated, and most cases have spontaneous resolution. If this fails treatment can still be started. Regular sonographic imaging of infants under treatment also allows progress towards location to be monitored, and harness treatment to be abandoned earlier when there is no satisfactory progress. In our opinion this, with the associated weekly supervision of the harness, is the principal factor for the complete lack of any complications from harness treatment in our study.

No benefits in any form have been received or will be received from a commercial party related directly or indirectly to the subject of this article.

\section{REFERENCES}

Barlow TG. Early diagnosis and treatment of congenital dislocation of the hip. J Bone Joint Surg [Br] 1962; 44-B:292-301.

Bjerkreim I. Congenital dislocation of the hip joint in Norway. Acta Orthop Scand 1974; Suppl 157.

Bradley J, Wetherill M, Benson MKD. Splintage for congenital dislocation of the hip: is it safe and reliable? J Bone Joint Surg [Br] 1987; 69B:257-63.

Burger BJ, Burger JD, Bos CFA, et al. Neonatal screening and staggered early treatment for congenital dislocation or dysplasia of the hip. Lancet 1990; 336:1549-53.

Catford JC, Bennet GC, Wilkinson JA. Congenital hip dislocation: an increasing and still uncontrolled disability? Br Med J 1982; 285: 1527-30.

Clarke NMP. Sonographic clarification of the problems of neonatal hip instability.J Pediatr Orthop 1986; 6:527-32.

Clarke NMP, Harcke HT, McHugh P, et al. Real-time ultrasound in the diagnosis of congenital dislocation and dysplasia of the hip. $J$ Bone Joint Surg [Br] 1985; 67-B:406-12.

Clarke NMP, Clegg J, Al-Chalabi AN. Ultrasound screening of hips at risk for $\mathrm{CDH}$ : failure to reduce the incidence of late cases. $J$ Bone Joint Surg [Br] 1989; 71-B:9-12.
Cunningham KT, Moulton A, Benningfield SA, Maddock CR. A clicking hip in a newborn baby should never be ignored. Lancet 1984; i: 668-70.

Dunn PM. Clicking hips should be ignored [Letter]. Lancet 1984; i:846.

Dunn PM, Evans RE, Thearle MJ, Griffiths HED, Witherow PJ. Congenital dislocation of the hip: early and late diagnosis and management compared. Arch Dis Child 1985; 60:407-14.

Harris LE, Lipscomb PR, Hodgson JR. Early diagnosis of congenital dysplasia and congenital dislocation of the hip: value of the abduction test. J Am Med Assoc 1960; 173:229-33.

Hiertonn T, James $\mathbf{U}$. Congenital dislocation of the hip: experiences of early diagnosis and treatment. J Bone Joint Surg [Br] 1968; 50-B: 542-5.

Kalamchi A, MacEwen GD. Avascular necrosis following treatment of congenital dislocation of the hip. J Bone Joint Surg [Am] 1980; 62A:876-88.

Langkamer VG, Clarke NMP, Witherow P. Complications of splintage in congenital dislocation of the hip. Arch Dis Child 1991; 66:1322-5.

Leck I. An epidemiological assessment of neonatal screening for dislocation of the hip. J R Coll Physicians Lond 1986; 20:56-62.

Lehmann EC, Street DG. Neonatal screening in Vancouver for congenital dislocation of the hip. Can Med Assoc J 1981; 124:1003-8.

Lennox IAC, McLauchlan I, Murali R. Failures of screening and management of congenital dislocation of the hip. J Bone Joint Surg [Br] 1993; 75-B:72-5.

MacKenzie IG. Congenital dislocation of the hip: the development of a regional service. J Bone Joint Surg [Br] 1972; 54-B:18-39.

MacKenzie IG, Wilson JG. Problems encountered in the early diagnosis and management of congenital dislocation of the hip. $J$ Bone Joint Surg [Br] 1981; 63-B:38-42.

Mitchell GP. Problems in the early diagnosis and management of congenital dislocation of the hip. J Bone Joint Surg [Br] 1972; 54-B:4-12.

Ortolani M. Un segno poco noto e sua importanza per la diagnosi precoce di prelussazione conenita dell'anca. Pediatria 1937; 45:129-36.

Place MJ, Parkin DM, Fitton JM. Effectiveness of neonatal screening for congenital dislocation of the hip. Lancet 1978; 2:249-50.

von Rosen S. Further experience with congenital dislocation of the hip joint in the newborn. J Bone Joint Surg [Br] 1968; 50-B:538-41.

Sanfridson J, Redlund-Johnell I, Udén A. Why is congenital dislocation of the hip still missed? Analysis of 96,891 infants screened in Malmö 1956-1987. Acta Orthop Scand 1991; 62:87-91.

Severin E. Frekvensen av luxatio coxae congenita och pes equinovarus congenitus i Sverige. Nord Med 1956; 55:221-3.

Tönnis D, Storch K, Ulbrich H. Results of newborn screening for CDH with and without sonography and correlation of risk factors. J Pediatr Orthop 1990; 10:145-52.

Williamson J. Difficulties of early diagnosis and treatment of congenital dislocation of the hip in Northern Ireland. J Bone Joint Surg [Br] 1972; 54-B:13-17. 